\title{
MEMBANDINGKAN KINERJA MESIN BENSIN DUA LANGKAH SATU SILINDER PADA SEPEDA MOTOR MENGGUNAKAN VARIASI CAMPURAN BAHAN BAKAR MINYAK HASIL PROSES PIROLISIS SAMPAH PLASTIK DAN PREMIUM DENGAN PREMIUM MURNI
}

\author{
Wardoyo \\ Teknik Mesin \\ Universitas Proklamasi 45 \\ Jl. Proklamasi No. 1 Babarsari Depok Yogyakarta
}

\begin{abstract}
This research was aimed to know the performance of engine using variation of plastic waste pyrolysis and premium process result-gasoline fuel mix and pure premium and comparing with pure premium. The fuel mix variation used consisted of $20 \%$ plastic waste pyrolysis process result oil, $80 \%$ premium and $49 \%$ plastic waste pyrolysis process result oil, $60 \%$ premium.

The research procedures included firstly the tested engine given pure premium fuel and the engine was run for 2-3 minutes by installing a transmission gear in 4 th position, then rotation, torsion, power and specific fuel consumption was measured. Furthermore, the engine was stopped and the fuel was substituted with varied plastic waste pyrolysis process result oil mix, the engine was re-run. The measurement rotations, torsion, power and specific fuel construction was conducted by the same way with pure premium fuel testing.

Out of test results for the same rotation of 5000-8000 engine RPM using fuel mix of 20\% plastic waste pyrolysis process result oil the average power was $10.04 \mathrm{HP}$, average torsion of $11.10 \mathrm{Nm}$, specific fuel consumption of $0.100 \mathrm{~kg}$ /hour HP and engine using fuel mix of $40 \%$ plastic waste pyrolysis process result oil the average power was $9.7 \mathrm{HP}$, average torsion of $10.82 \mathrm{NM}$, specific fuel consumption of $0.068 \mathrm{~kg}$ hour HP. While using pure premium the average power was $9.8 \mathrm{HP}$, average torsion of $10.94 \mathrm{Nm}$, specific fuel consumption was $0.103 \mathrm{~kg}$ hour HP.

If compared, so that engine performance using fuel mix of $40 \%$ plastic waste pyrolysis process result oil and $60 \%$ premium almost approached engine performance using pure premium fuel and actually $20 \%$ fuel mix of plastic waste pyrolysis process result oil and $80 \%$ premium was better.
\end{abstract}

Keywords: Gasoline two cylinder engine performance, Plastic waste pyrolysis process result oil

\begin{abstract}
Abstrak
Tujuan Penelitian ini adalah untuk mengetahui kinerja dari mesin dengan menggunakan variasi campuran bahan bakar minyak hasil proses pirolisis sampah plastik dengan premium dan membandingkannya dengan premium murni. Adapun variasi campuran bahan bakar yang digunakan terdiri dari $20 \%$ minyak hasil proses pirolisis sampah plastik, $80 \%$ premium dan $40 \%$ minyak hasil proses pirolisis sampah plastik, $60 \%$ premium.

Cara penelitian yaitu mula-mula mesin yang diuji diberi bahan bakar premium murni dan mesin dijalankan selama 2 - 3 menit dengan memasang gear transmisi pada posisi ke-4, kemudian putaran, torsi, daya dan konsumsi bahan bakar spesifik diukur. Setelah itu mesin dihentikan dan bahan bakar diganti dengan campuran minyak hasil proses pirolisis sampah bervariasi, kemudian mesin dijalankan kembali. Pengukuran putaran-putaran, torsi, daya dan konstruksi bahan bakar spesifik dilakukan dengan cara yang sama dengan pengujian bahan bakar premium murni.
\end{abstract}


Dari hasil pengujian untuk putaran yang sama yaitu 5000 - 8000 rpm mesin dengan menggunakan campuran bahan bakar $20 \%$ minyak hasil proses pirolisis sampah plastik daya rata-rata $10,04 \mathrm{HP}$, torsi rata-rata $11,10 \mathrm{Nm}$, konsumsi bahan bakar spesifik $0,100 \mathrm{~kg} / \mathrm{HP}$ jam dan mesin dengan menggunakan campuran bahan bakar $40 \%$ minyak hasil proses pirolisis sampah plastik daya rata-rata $9,7 \mathrm{HP}$, torsi rata-rata $10,82 \mathrm{Nm}$, konsumsi bahan bakar spesifik $0,068 \mathrm{~kg} / \mathrm{HP}$ jam. Sedangkan menggunakan premium murni daya rata-rata $9,80 \mathrm{HP}$, torsi rata-rata $10,94 \mathrm{Nm}$, konsumsi bahan bakar spesifik $0,103 \mathrm{~kg} / \mathrm{HP}$ jam.

Jika dibandingkan maka kinerja mesin dengan menggunakan campuran bahan bakar $40 \%$ minyak hasil proses pirolisis sampah plastik dan $60 \%$ premium hampir mendekati kinerja mesin dengan menggunakan bahan bakar premium murni, dan ternyata campuran bahan bakar $20 \%$ minyak hasil pirolisis sampah plastik dan $80 \%$ premium lebih baik.

Kata kunci: Kinerja mesin bensin dan langkah minyak hasil pirolisis sampah plastik

\section{Pendahuluan}

Sepeda motor merupakan alat transportasi yang banyak digunakan oleh setiap orang dalam kehidupan sehari-hari. Setiap pengguna sepeda motor menghendaki kineja mesin yang baik dan ekonomis.

Penelitian ini kajiannya adalah membandingkan kinerja mesin bensin dua langkah satu silinder pada sepeda motor dengan menggunakan variasi campuran bahan bakar minyak hasil proses pirolisis sampah plastik dengan premium murni. Adapun variasi campurannya terdiri dari $20 \%$ minyak hasil proses priolisis sampah plastik $80 \%$ premium dan $60 \%$ minyak hasil proses pirolisis sampah plastik $40 \%$ premium.

Dalam penelitian ini menggunakan mesin bensin dua langkah satu silinder karena angka oktan bahan bakar, perbandingan kompresi dan sentifitas bahan bakar lebih rendah jika dibanding dengan mesin bensin empat langkah satu silinder. Di samping itu pembersihan kerak karbon (deposit) yang menempel pada permukaan kepala corak pada mesin bensin dua langkah lebih mudah dibersihkan jika dibanding dengan mesin bensin empat langkah.

\section{Metode Penelitian}

Penelitian dilakukan di laboratorium Teknik Mesin Universitas Proklamasi 45 Yogyakarta.

\subsection{Bahan Penelitian}

Bahan yang digunakan untuk penelitian yaitu :

1. Premium murni

2. Campuran bahan bakar $20 \%$ minyak hasil proses pirolisis sampah plastik dan $80 \%$ premium

3. Campuran bahan bakar $40 \%$ minyak hasil proses pirolisis sampah plastik dan $60 \%$ premium.

\subsection{Alat Penelitian}

Sebagai alat uji pada penelitian ini digunakan sepeda motor dua langkah merk Suzuki Satria 120 R. Berikut ini gambar instalasi pengujian kinerja mesin. 


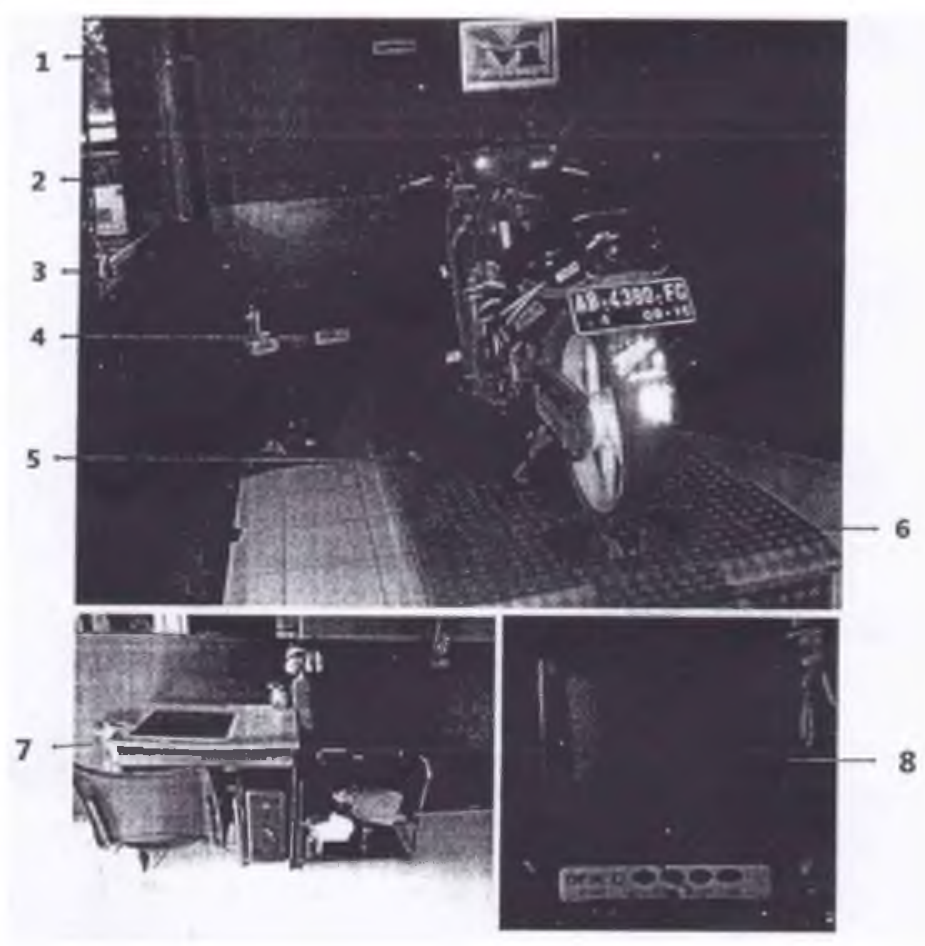

Keterangan Gambar

1. Monitor Output

2. Buret Ukur

3. Thermo Hygrometer Deko 637

4. Sensor Pembaca Beban dan RPM

5. Pengikat Kendaraan

6. Roller Bed

7. Komputer Olah Data

Gambar 1. Instalasi Pengujian Kinerja Mesin Bensin Dua Langkah Merk Suzuki Satria 120 R

\subsection{Cara Pengujian}

Mesin diberi bahan bakar premium murni, kemudian dijalankan selama 2-3 menit. Gear transmisi diatur ke posisi 4 dan gas idle diputar hingga putaran mesin mencapai $5000 \mathrm{rpm}$ sampai $8000 \mathrm{rpm}$. Selanjutnya daya, torsi maksimal diukur. Selesai pengukuran mesin dihentikan. Bahan bakar dikeluarkan (dibersihkan) dan diganti dengan variasi campuran bahan bakar minyak hasil proses pirolisis sampah plastik. Mesin dijalankan lagi selama 2-3 menit. Pengukuran daya dan torsi maksimal dilakukan dengan cara yang sama. Data yang pengujian digunakan sebagai bahan perbandingan.

\section{Hasil Penelitian dan Pembahasan}

\subsection{Hasil Penelitian}

Data hasil penelitian terdiri dari :

1. Data Pengukuran Torsi

Tabel 1. Data Torsi

\begin{tabular}{ccccc}
\hline & & \multicolumn{3}{c}{ Torsi (Nm) } \\
\cline { 3 - 5 } No. & \multirow{4}{*}{ RPM } & Premium & $\begin{array}{c}\text { Premium }+20 \% \\
\text { minyak plastik }\end{array}$ & $\begin{array}{c}\text { Premium }+40 \% \\
\text { minyak plastik }\end{array}$ \\
\cline { 3 - 5 } & & 11,47 & 10,64 & 11,25 \\
\cline { 3 - 5 } 1 & 5000 & 12,17 & 11,08 & 11,90 \\
2 & 5500 & 13,05 & 12,63 & 13,14 \\
3 & 6000 & 12,83 & 13,35 & 13,18 \\
4 & 6500 & 11,50 & 12,79 & 11,71 \\
5 & 7000 & 8,41 & 9,93 & 7,62 \\
6 & 7500 & 7,14 & 7,28 & 0,98 \\
7 & 8000 & 10,94 & 11,10 & 10,82 \\
\hline \multicolumn{2}{c}{ Nilai rata-rata } & \multicolumn{3}{c}{} \\
\hline
\end{tabular}


2. Data Pengukuran Daya

Tabel 2. Data Daya

\begin{tabular}{ccccc}
\hline & & \multicolumn{3}{c}{ Torsi (Nm) } \\
\cline { 3 - 5 } No. & RPM & Premium & $\begin{array}{c}\text { Premium }+20 \% \\
\text { minyak plastik }\end{array}$ & $\begin{array}{c}\text { Premium }+40 \% \\
\text { minyak plastik }\end{array}$ \\
\cline { 3 - 5 } & & 8,10 & 7,50 & 7,90 \\
\hline 1 & 5000 & 9,40 & 8,60 & 9,20 \\
2 & 5500 & 11,00 & 10,70 & 11,10 \\
3 & 6000 & 11,80 & 12,20 & 12,10 \\
4 & 6500 & 11,30 & 12,60 & 11,60 \\
5 & 7000 & 8,90 & 10,50 & 8,10 \\
6 & 7500 & 8,10 & 8,20 & 7,90 \\
7 & 8000 & 9,80 & 10,04 & 9,7 \\
\hline \multicolumn{2}{c}{ Nilai rata-rata } & & & \\
\hline
\end{tabular}

3. Data Pengukuran Konsumsi Bahan Bakar Spesifik

Tabel 3. Data Konsumsi Bahan Bakar Spesifik

\begin{tabular}{ccccc}
\hline & & \multicolumn{3}{c}{ Konsumsi Bahan Bakar Spesifik (SFC) kg/HP jam } \\
\cline { 3 - 5 } No. & RPM & \multicolumn{3}{c}{ Bahan bakar yang digunakan } \\
\cline { 3 - 5 } & 5000 & Premium & $\begin{array}{c}\text { Premium }+20 \% \\
\text { minyak plastik }\end{array}$ & $\begin{array}{c}\text { Premium }+40 \% \\
\text { minyak plastik }\end{array}$ \\
\hline 1 & 0,103 & 0,100 & 0,068 \\
\hline
\end{tabular}

\subsection{Pembahasan}

Pengolahan (perhitungan) data hasil penelitian menggunakan persamaan-persamaan berikut ini :

1) Laju Konsumsi Bahan Bakar Spesifik : mf

$$
\mathrm{mf}=\frac{b}{t} 3,6 \rho_{b b}(\mathrm{~kg} / \mathrm{jam})
$$

2) Konsumsi Bahan Bakar Spesifik : SFC

$$
\mathrm{SFC}=\frac{m f}{P}(\mathrm{~kg} / \mathrm{HP} \mathrm{jam})
$$

Dengan : $\quad \mathrm{b}=$ volume buret yang digunakan dalam pengujian (cc)

$\mathrm{t} \quad=$ waktu yang digunakan untuk pengosongan buret (detik)

$\rho_{b b}=$ massa jenis bahan bakar premium $(0,73 \mathrm{gram} / \mathrm{cc})$

$\mathrm{P} \quad=$ Daya yang diukur (HP) 
Dari hasil pengolahan data dapat dibuat grafik untuk membuat pembahasan

1) Grafik Hubungan Torsi dan Putaran

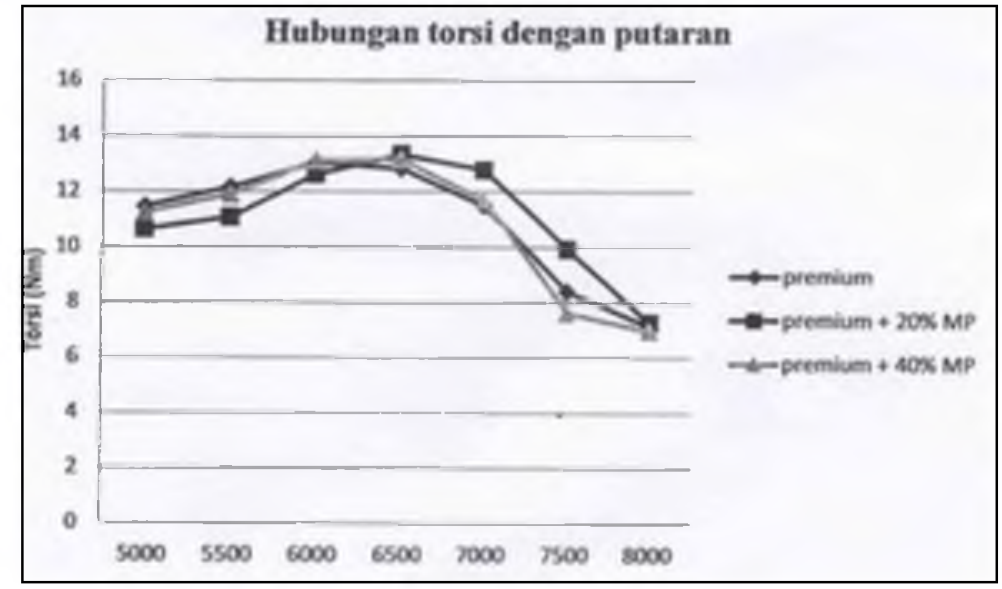

Gambar 2. Grafik hubungan Torsi dan Putaran

Dari grafik hubungan torsi dan putaran terlihat adanya kenaikan torsi pada bahan bakar premium dengan campuran $20 \%$ minyak hasil proses pirolisis sampah plastik seiring dengan naiknya angka oktan bahan bakar tersebut pada putaran $6500 \mathrm{rpm}$. Hal ini disebabkan bahwa pada putaran $6500 \mathrm{rpm}$ bahan bakar tersebut lebih mudah terbakar karena sifat viskositasnya. Sedangkan pada bahan bakar premium pada putaran 6500 rpm akan mengalami sangat mudahnya bahan bakar tersebut terbakar sehingga menyebabkan banyaknya kerugian energi untuk menghasilkan torsi.

\section{2) Grafik Hubungan Daya dan Putaran}

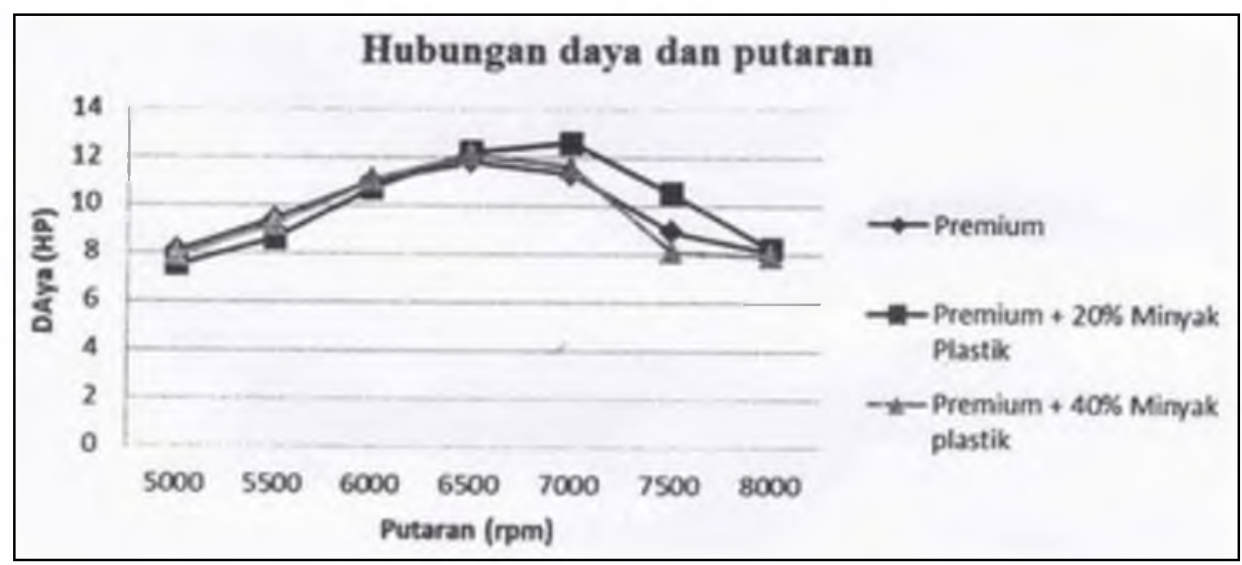

Gambar 3. Grafik Hubungan Daya dan Putaran

Dari grafik hubungan daya dan putaran terlihat bahwa meningkatnya daya mesin pada bahan bakar premium dengan campuran $20 \%$ minyak hasil proses pirolisis sampah plastik disebabkan karena viskositas bahwa bahan menurun sehingga saat diinjeksikan ke dalam ruang bakar dapat membentuk butiran-butian kabut yang lebih halus. Dengan kondisi seperti ini maka proses pencampuran udara dan bahan bakar lebih homogen dan semakin mudah terbakar, maka waktu pembakaran bahan bakar semakin singkat. Hal ini menjadikan tekanan yang ada di ruang bakar semakin besar dan menghasilkan daya yang lebih besar. 
Wardoyo

\subsection{Konsumsi bahan bakar spesifik}

Berdasarkan hasil pengujian menggunakan bakar premium, premium dengan campuran $20 \%$ minyak plastik, dan dengan campuran 40\% minyak plastik, diperoleh data konsumsi bahan bakar spesifik (Tabel 3). Menggunakan variasi campuran bahan bakar ternyata konsumsi bahan bakarnya lebih ekonomis dan daya yang dihasilkan besar.

Pada bahan bakar premium pada putaran tinggi (5000 rpm ke atas) mengakibatkan detonasi yang mengakibatkan kerugian pada proses pembakaran. Detonasi atau sering juga disebut "knocking" adalah pembakaran explosive dalam silinder yang jauh lebih cepat daripada pembakaran normal. Detonasi dapat terjadi pada semua jenis motor bakar dan bersifat sangat merugikan karena mampu merusak komponen silinder atau ruang bakar serta menurunkan daya dari mesin. Pada motor bakar 2 langkah, akan lebih mudah mengalami detonasi daripada motor bahan bakar 4 langkah.

\section{Kesimpulan}

Berdasarkan hasil analisa penggunaan bahan bakar premium murni, premium dicampur $20 \%$ dan $40 \%$ minyak hasil proses pirolisis sampah plastik pada mesin bensin dua langkah satu silinder pada sepeda motor maka dapat dibuat kesimpulan bahwa :

1. Bahan bakar dengan campuran $20 \%$ minyak hasil proses pirolisis sampah plastik lebih baik karena menghasilkan daya dan torsi yang tinggi sebesar 12,60 HP dan 13,35 Nm untuk putaran yang sama sebesar $6500 \mathrm{rpm}$.

2. Variasi campuran bahan bakar premim dengan minyak hasil proses pirolisis sampah plastik berpengaruh terhadap performa mesin. Untuk campuran $20 \%$ minyak hasil proses pirolisis sampah plastik performa mesin lebih baik dan konsumsi bahan bakar spesifik lebih ekonomis.

\section{Daftar Pustaka}

Agustriana, Vera. $201 \quad$ 1. Alat ukur dan ketelitian. http://mototech.co.idlindexphp?action=store.showCat\&cat id=39. Diakses tanggal 25 maret 2015 pukul 16.21 WIB.

Andyana, LW. Bandem. 2013. Sistem Penyaluran Bahan Bakar (Fuel System). http:/web.ipb.ac.id/ tepfteta/elearning/media/Bahan\%20Ajar\%20Motor\%20dan\%20T enaga\%20Pertanian/P\%20gatot/Sistem\%20BBYo20\&\%20Pelumasan\%20$\% 20 N E W . h t m$. Diakses 3 maret 2015.

Arismunandar, Wiranto. 1983. Penggerak Mula Motor Bakar Torak. Penerbit ITB. Bandung, hal: 4-30.

Aydinli, B., Caglar, A. 2013. The comparison of hazelnut shell co-pyrolysis with polyethylene oxide and previous ultra-high molecular weight polyethylene. Journal of Analytical and Applied Pyrolysis, 87 (2):263-268

Besier S. and Williams T.P. 1996. The Influence of Temperature and Heating Rate on The Slow Pyrolysis of Biomass. Journal Renewable Energy, 7(3): 223-317. 
Dirjen migas. 2006. Kep. Direktur Jenderal Minyak dan gas bumi No. SK Dirjen Migas No. $3674 \mathrm{KJ} 24 / \mathrm{DJM} / 2006$.

Handoko, Tri. 2011. Mengubah Limbah Plastik Jadi Bahan Bakar Minyak Https:/indonesiaproud.wordpress.com/2011/12/01/tri-handoko-mengubah-limbahplastik jadi-bahan-bakar-minyak! Diakses tanggal 3 maret 2015.

Hastuti, Dyah Woro. 2013. Konsep reaksi pembakaran. http://eprints.undip.ac.idI41619/3/BAB II.pdf. Diakses tanggal 1 maret 2015.

Irfan, Ahmad. 2013. Teori Dasar Motor Bakar. http://abangirfan62.blogspot.com/2013/06/teoridasar-motor-bakar.html. Diakses tanggal 5 maret 2015.

Johnson, Matthew and Sean Derrick. 2013. Pyrolysis: A method for Mixed Polymer Recycling. Micighan, Western Micighan University. Pp. 4-18.

Kumar S., Panda, A.K., dan Singh, R.K.. 2011. A Review on Tertiary Recycling of HighDensity Polyethylene to Fuel. Resources, Conservation and Recycling, 55: 893-910.

Lesmana, Faizal. 2014. Sistem Pengapian (Ignition System). http:/zallesmana.blogspot.com/p/sistem pengapian-ignition-system.html. Diakses tanggal 4 maret 2015. 
Wardoyo 